\title{
NEW CURRENT-MODE OSCILLATORS USING UNITY-GAIN CURRENT-FOLLOWERS
}

\author{
MUHAMMAD TAHER ABUELMA'ATTI \\ King Fahd University of Petroleum and Minerals \\ Box 203 Dhahran 31261 Saudi Arabia
}

(Received October 8, 1994; in final form December 29, 1994)

\begin{abstract}
A catalog of current-mode oscillator circuits using negative unity-gain current-followers is presented. Each circuit uses two unity-gain current-followers, three resistors, and three capacitors. Simulation results obtained from two new circuits are presented.
\end{abstract}

\section{INTRODUCTION}

Recently, a number of current-mode RC-oscillator circuits using a single currentfollower has been presented [1,2]. Unfortunately, none of these circuits use a true current-follower with unity gain as they require a current-gain greater than unity.

A current-follower is usually obtained from a second-generation current-conveyor by grounding its high impedance terminal. Although a discrete-element implementation of a current-conveyor with variable-gain has been reported [3] this requires additional active devices, which makes their IC implementation too much complex. Thus, the realization of oscillators using unity-gain current followers would be attractive as they can be implemented using available second-generation current-conveyor integrated circuits.

\section{PROPOSED CIRCUITS}

Consider the oscillator structures shown in Fig. 1. Assuming ideal current-followers with $i_{y}=i_{x}$ and $v_{x}=0$ routine analysis of the circuits of Fig. 1 for unity loop-gain of current, yields the characteristic equation given by

$$
\left(Y_{3}\left(Y_{4}+Y_{5}\right)+Y_{4} Y_{5}\right)\left(Y_{1}+Y_{2}+Y_{6}\right)+Y_{1} Y_{4} Y_{6}=0
$$

for the structure of Fig. 1(a),

$$
\left(Y_{3}\left(Y_{2}+Y_{6}\right)+Y_{2} Y_{6}\right)\left(Y_{1}+Y_{4}+Y_{5}\right)+Y_{1} Y_{3} Y_{5}=0
$$

for the structure of Fig. 1(b),

$$
Y_{5} Y_{6}\left(Y_{1}+Y_{2}+Y_{3}+Y_{4}\right)+Y_{3} Y_{5}\left(Y_{1}+Y_{4}\right)+Y_{4} Y_{6}\left(Y_{2}+Y_{3}\right)=0
$$

for the structure of Fig. 1(c),

$$
Y_{4} Y_{5}\left(Y_{1}+Y_{2}+Y_{3}+Y_{6}\right)+Y_{2} Y_{3}\left(Y_{5}+Y_{6}\right)+Y_{6}\left(Y_{2} Y_{5}+Y_{3} Y_{4}\right)=0
$$



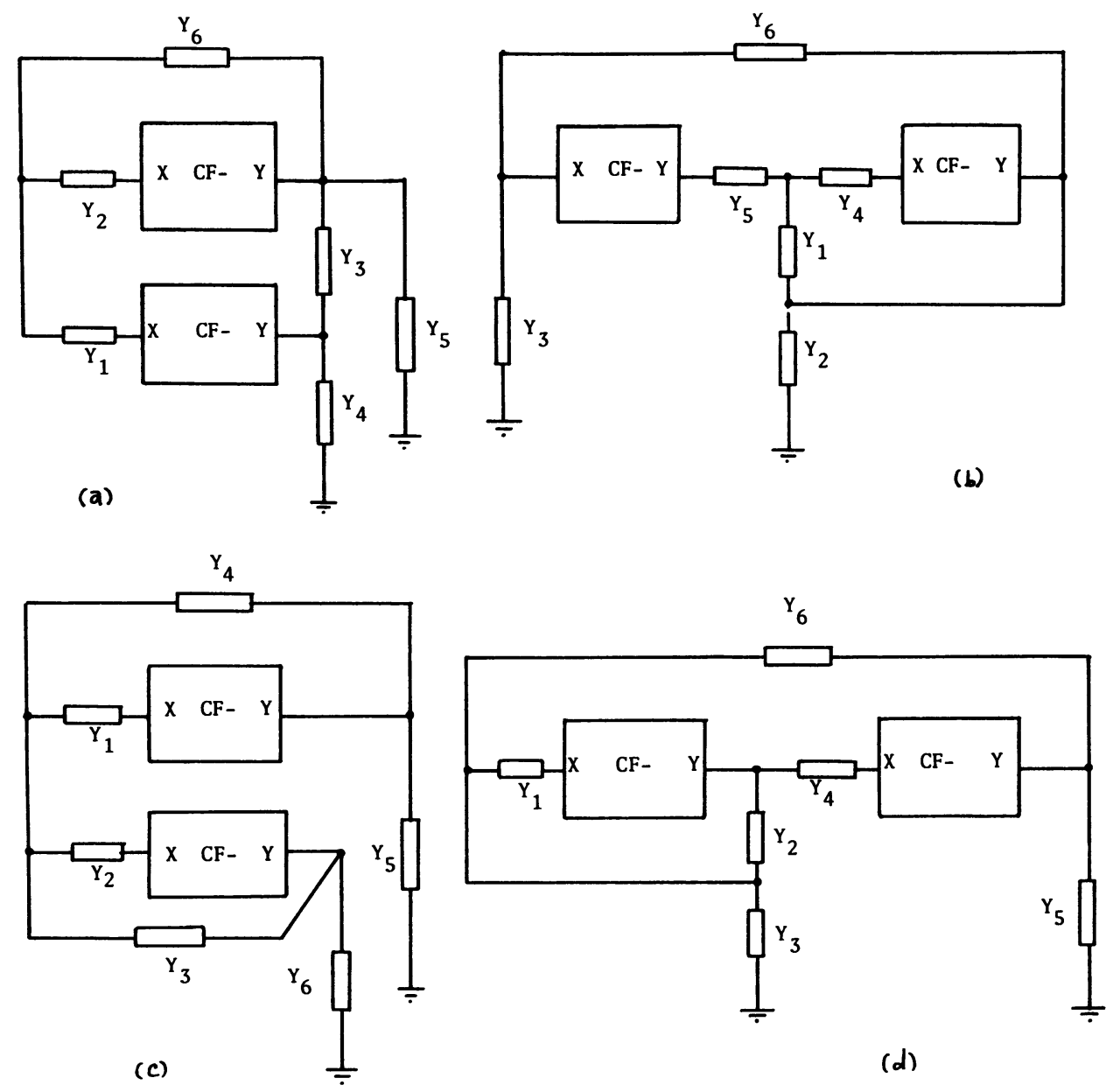

(c)

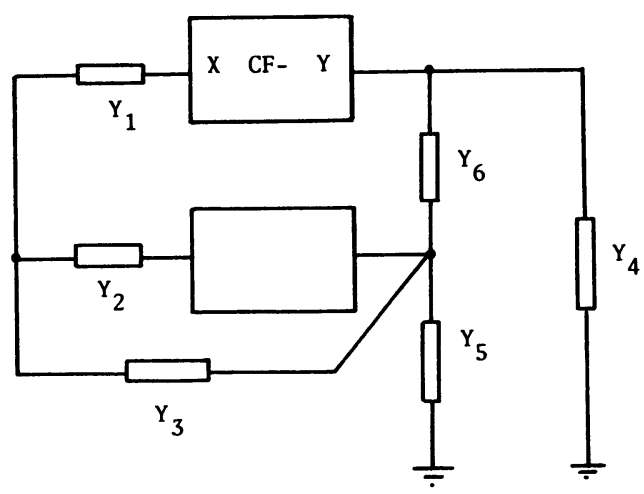

FIGURE 1 Proposed Oscillator Structures 


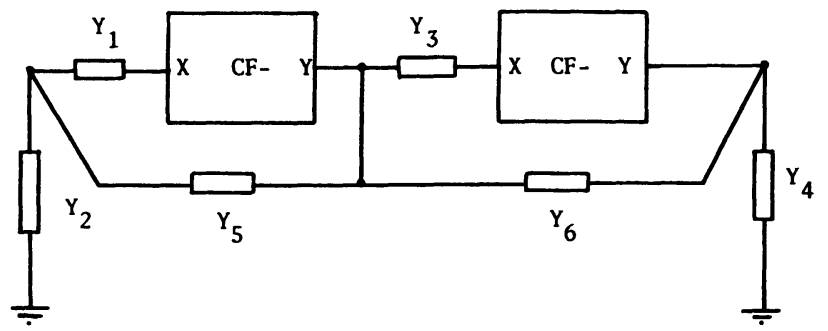

$(f)$

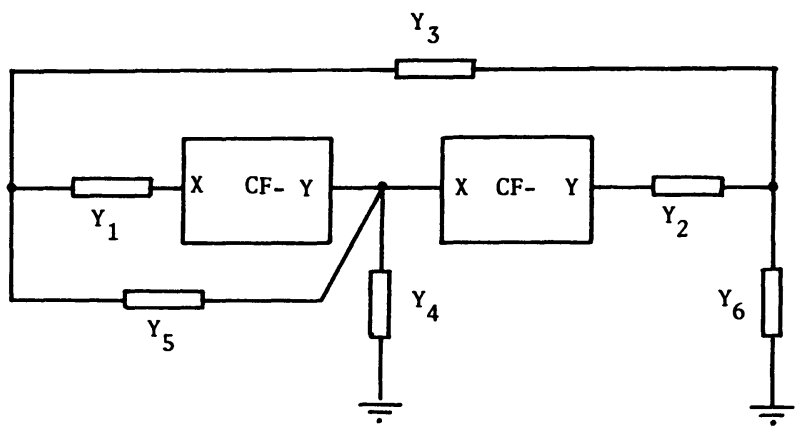

(9)

FIGURE 1 (Continued)

for the structure of Fig. 1(d),

$Y_{1} Y_{4}\left(Y_{3}+Y_{5}+Y_{6}\right)+Y_{5} Y_{6}\left(Y_{1}+Y_{2}+Y_{3}\right)+Y_{4}\left(Y_{5}+Y_{6}\right)\left(Y_{2}+Y_{3}\right)=0$

for the structure of Fig. 1(e),

$Y_{4}\left(Y_{3}+Y_{6}\right)\left(Y_{1}+Y_{2}+Y_{5}\right)+Y_{2} Y_{5}\left(Y_{4}+Y_{6}\right)=0$

for the structure of Fig. 1(f), and

$Y_{4}\left(Y_{1}+Y_{5}\right)\left(Y_{2}+Y_{3}+Y_{6}\right)+Y_{3}\left(Y_{4}\left(Y_{2}+Y_{6}\right)+Y_{5} Y_{6}\right)=0$

for the circuit of Fig. 1(g).

Using equations (1)-(7) oscillator circuits can be derived from the structures of Fig. 1(a)-1(g), respectively. Table I shows the admittances, the frequencies of oscillation, and the conditions of oscillation of the obtained circuits. It is interesting to note that by interchanging the resistors and capacitors of Table I, another set of oscillator circuits is obtainable.

\section{SIMULATION RESULTS}

The oscillator circuits proposed in this paper have been checked using PSPICE Student Version 5.0a. Although there are several ways to simulate the current-follower required, the simulation was performed using a second-generation currentconveyor CCII. The current-follower can be obtained using a CCII with its high impedance terminal grounded. The CCII was simulated using the circuit proposed by Senani [4] because of its simplicity. The kernel of the work presented here is independent of the particular simulation selected. The CCII was simulated using 


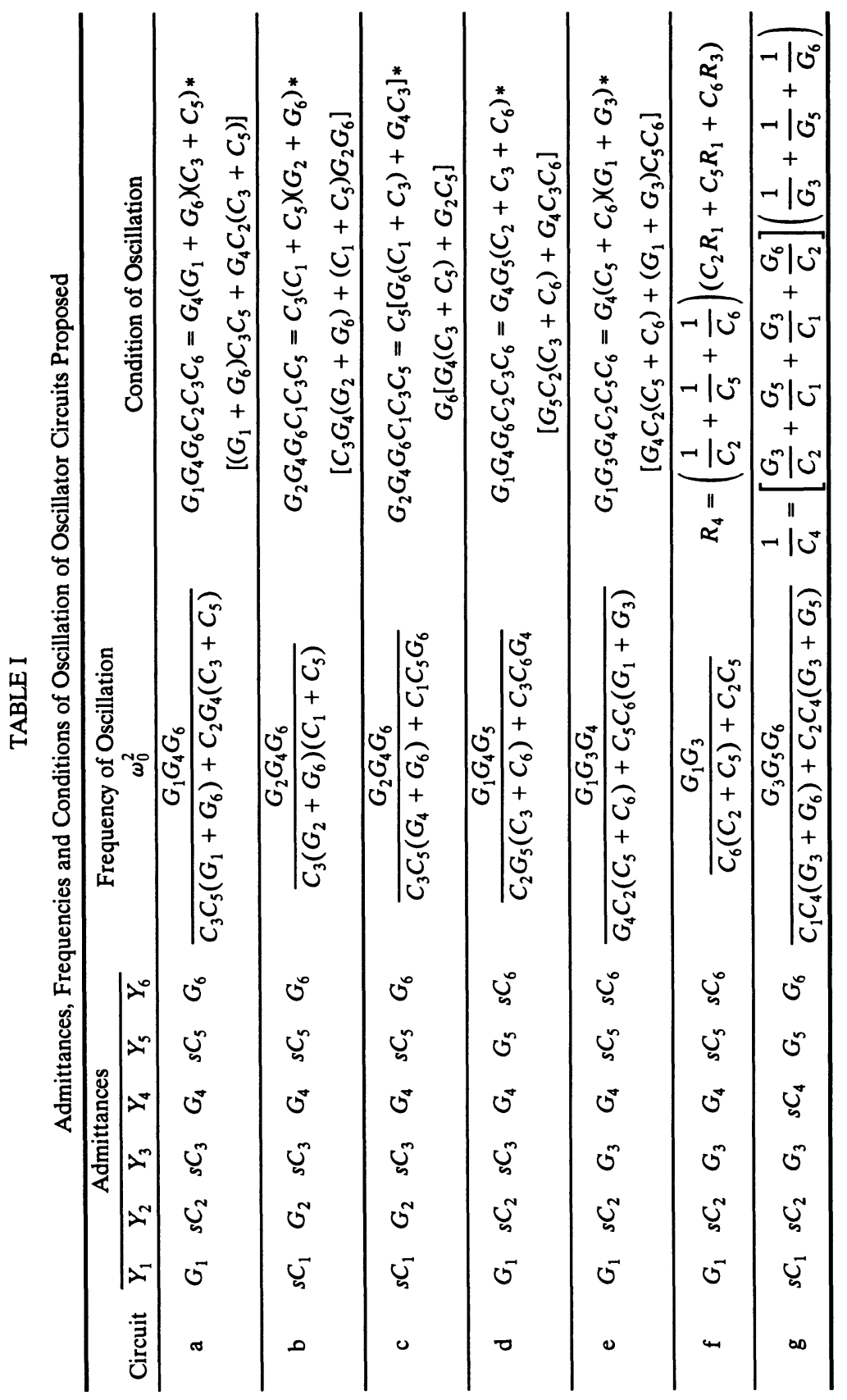




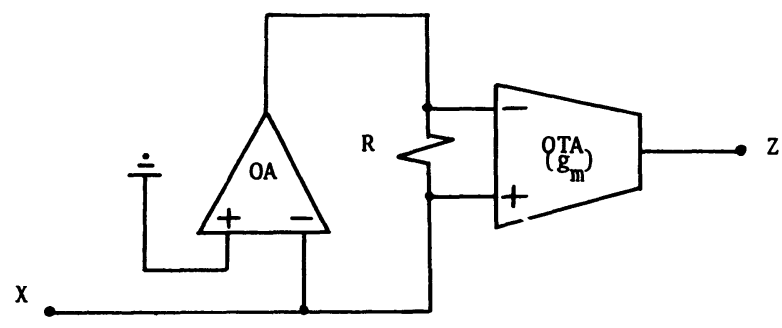

FIGURE 2 The circuit used for Simulating CF- $R=1 \mathrm{~K}, g_{\mathrm{m}}=1 \mathrm{~mA} / \mathrm{V}$.

one operational amplifier and one operational transconductance amplifier, as shown in Fig. 2. The operational amplifier was simulated using the uA741 model contained in the file called EVAL.LIB available in the PSPICE Student Version. The start of oscillation is caused by the offset voltage of the operational amplifier [5]. To demonstrate that the oscillations are self starting, the voltages across the capacitors are initialized at zero voltages. The operational transconductance amplifier was simulated assuming a finite input resistance of $2 \mathrm{MOhm}$. To avoid the possible latch-up resulting from the non-zero offset current at terminal $Y$ of the current-follower an antiparallel diode pair is connected between terminal $Y$ and the ground. Fig. 3(a) and (b) shows the simulated oscillations obtained from the circuits of Fig. 1(d) and 1(f). The simulation results are in good agreement with the theory presented.

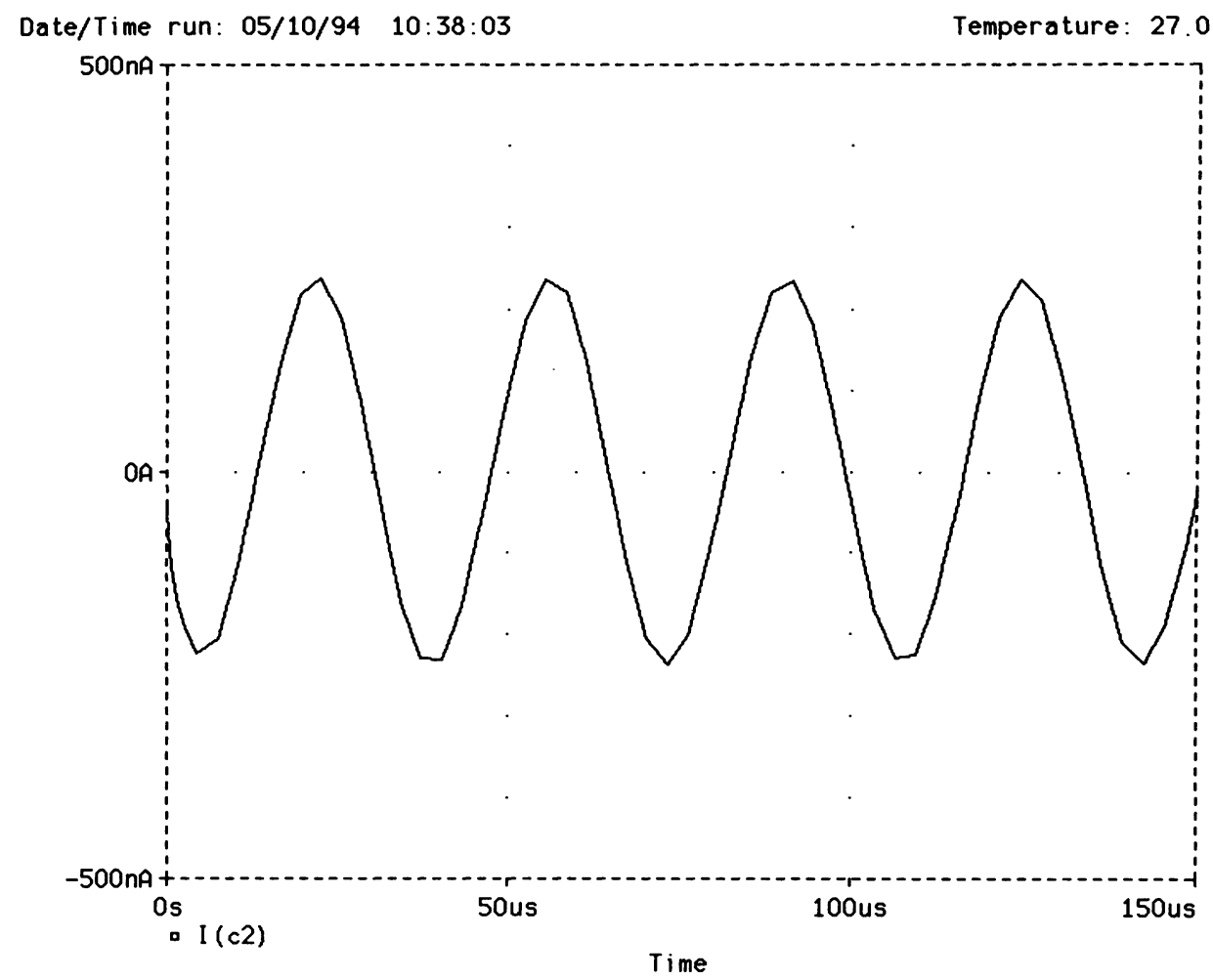

FIGURE 3 (a) Oscillations obtained from Fig. 1 (d) with $C_{2}=C_{3}=C_{6}=1 \mathrm{nF}, R_{1}=R_{3}=1 \mathrm{~K}$ and $\mathbf{R}_{\mathrm{u}}=8.2 \mathrm{~K}$ 


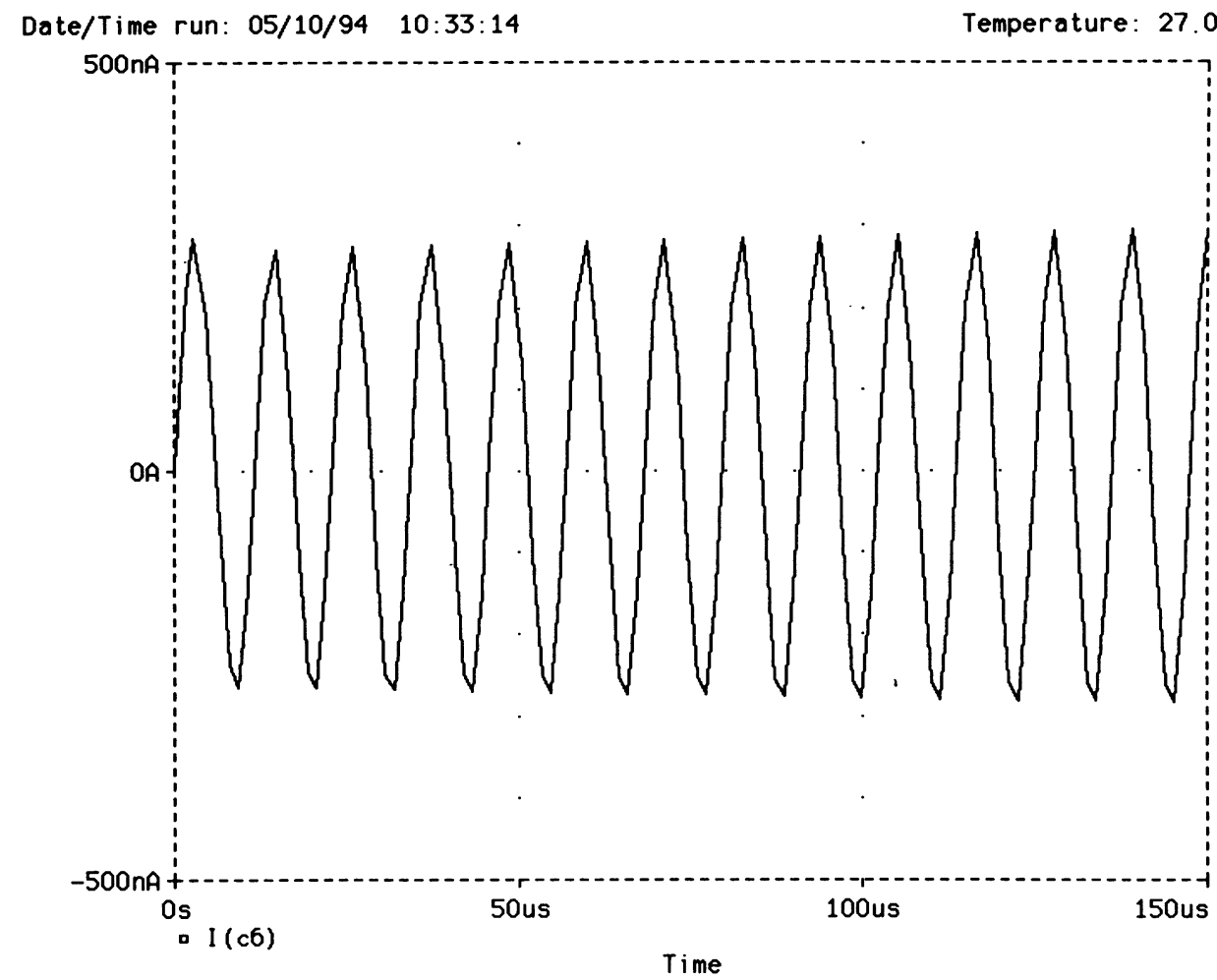

FIGURE 3 (b) Oscillations obtained from Fig. 1 (f) with $C_{2}=C_{5}=C_{6}=1 \mathrm{nF}, R_{1}=R_{3}=1 \mathrm{~K}$ and $R_{\mathrm{u}}=8.2 \mathrm{~K}$

\section{CONCLUSION}

In this paper, new oscillator circuits using unity gain current followers have been presented. Each circuit uses two current followers, three resistors, and three capacitors. The practical implementation of these oscillator circuits is straightforward, as they require unity-gain current-followers, which can be easily obtained from available IC second-generation current-conveyors by grounding their high impedance terminal.

\section{REFERENCES}

1. J.-J. Chen, C.-C. Chen, H.-W. Tsao and S.-I. Liu, Current-mode oscillators using single current follower, Electronics Letters, Vol. 27, 1991, pp. 2056-2059

2. M.T. Abuelma'atti, Grounded-capacitor current-mode oscillator using single current follower, IEEE Transactions on Circuits and Systems-I: Fundamental Theory and Applications, Vol. 39, 1992, pp. $1018-1020$

3. A. Carlosena and G.S. Moschytz, Design of variable-gain current conveyors, IEEE Transactions on Circuits and Systems-I: Fundamental Theory and Applications, Vol. 41, 1994, pp. 79-81

4. R. Senani, Novel circuit implementation of current conveyors using O.A. and an O.T.A., Electronics Letters, Vol. 16, 1980, pp. 2-3

5. G.W. Roberts and A.S. Sedra, SPICE for Microelectronics, Saunders College Publishing, 1992 

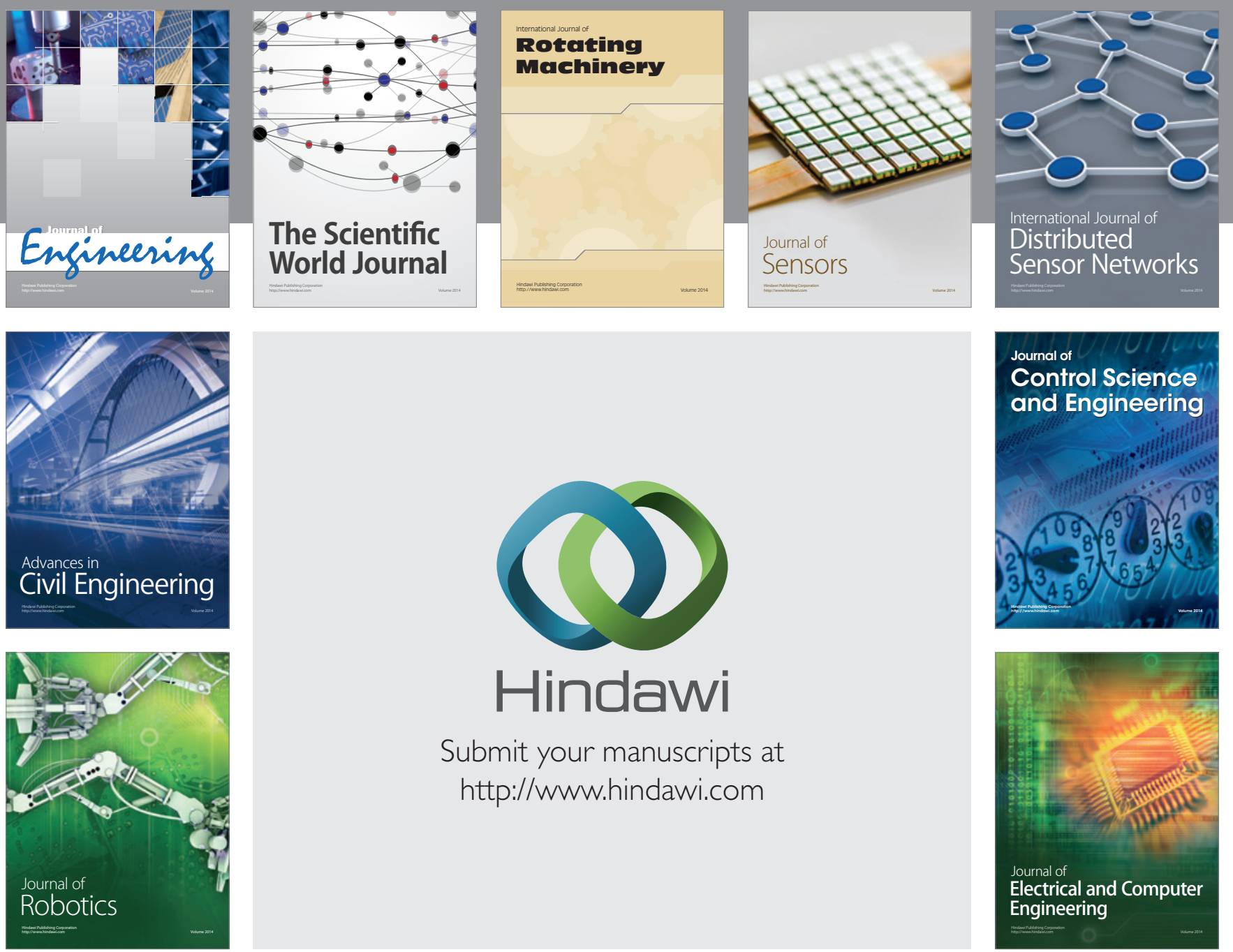

Submit your manuscripts at

http://www.hindawi.com
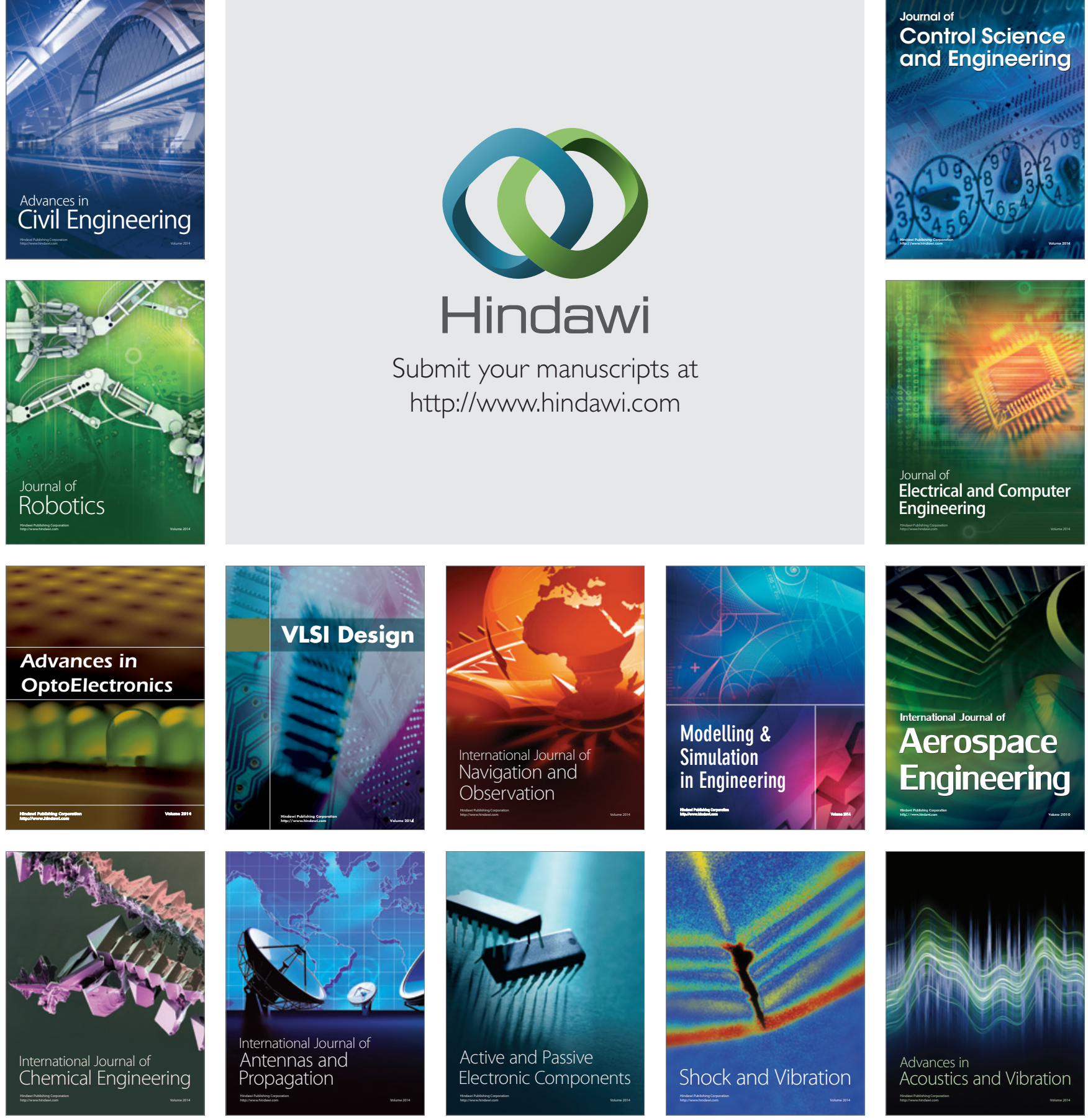